(3)

Volume 15, 2018

\title{
DECISION SUPPORT INFORMATION SYSTEM FOR URBAN LIGHTING
}

$\begin{array}{lll}\text { Michael Dreyfuss } & \begin{array}{l}\text { Jerusalem College of Technology, } \\ \text { Jerusalem, Israel }\end{array} & \text { dreyfuss@jct.ac.il } \\ \text { Yahel Giat* } & \begin{array}{l}\text { Jerusalem College of Technology, } \\ \text { Jerusalem, Israel }\end{array} & \text { yahel@jct.ac.il } \\ * \text { Corresponding author } & \end{array}$

\begin{abstract}
Aim/Purpose This paper describes an information system for the maintenance and management of municipal lighting systems that also serves as a decision support system for reducing power consumption on urban lighting.

Background

Many municipalities are financially constrained and unable to invest in improving their lighting infrastructure. We propose a very efficient and inexpensive way to set up the database and provide city leaders with tools to improve their system efficiently.

Methodology An information database for the data management and an Integer Programming model for deriving the optimal investment plan.

Contribution

This paper contributes to the fields of urban economics and sustainability.

Findings Informing management and workers about the status of the system and how to optimize it will reward the city with considerable savings and improve the service quality.

Recommendations The application of this model, even in a small scale such as a neighborfor Practitioners hood can improve citizen's quality of life without a heavy burden on the city budget.

Recommendation There is a growing need for cost-effective means to improve urban manfor Researchers agement. Innovative ideas that meet these goals should be researched and developed.
\end{abstract}

Accepting Editor: Eli Cohen | Received: December 21, 2017 | Revised: March 16, 2018 | Accepted: March 26, 2018.

Cite as: Dreyfuss, M., \& Giat, Y. (2018). Decision support information system for urban lighting. Issues in Informing Science and Information Technology, 15, 109-124. https://doi.org/10.28945/3995

(CC BY-NC 4.0) This article is licensed to you under a Creative Commons Attribution-NonCommercial 4.0 International License. When you copy and redistribute this paper in full or in part, you need to provide proper attribution to it to ensure that others can later locate this work (and to ensure that others do not accuse you of plagiarism). You may (and we encourage you to) adapt, remix, transform, and build upon the material for any non-commercial purposes. This license does not permit you to use this material for commercial purposes. 
DSS for Urban Lighting

Impact on Society First, it allows reduction in carbon emissions and light pollution by reducing power consumption and over-luminous lighting levels. Second, financially constrained municipalities can manage their systems at a very low cost.

Future Research A full scale application is needed in order to evaluate the city-wide benefits of the system.

Keywords energy efficiency, municipal budget, integer programming, optimization

\section{INTRODUCTION}

Urban lighting costs present a heavy budget burden on local governments. Even in wealthy countries, it is quite common to find municipalities and utility authorities that are constantly cash-strapped (Governing, 2017). As a consequence, many cities tend to ignore the need to update their infrastructure, leading to ageing and costly systems, which further strain their budget. This vicious cycle of increasing costs also results with more light-pollution and carbon-emitting.

Another powerful player in this field is the industry of lighting system, which has made tremendous progress in the recent decade. Street lighting accounts for $53 \%$ of the outdoor lighting use in the world, and in terms of energy is 115.54 Terawatt-hours (TWh) annually (Johansson et al. 2014). The market for smart lighting is expected to grow between year 2013 and 2020 from $0.4 \mathrm{~B} \$$ to $11.4 \mathrm{~B} \$$ (Jurvansuu \& Belloni, 2013, p.44). This tremendous expected growth explains the aggressive marketing effort by producers in the lighting industry.

This study addresses the "power-burning" problem of inefficient street lighting by developing an information system for the management and the maintenance of the street lighting infrastructure. This system has two critical elements that make it extremely beneficial for municipalities with limited budgets and ageing lighting infrastructure.

First, whereas many of the databases for these problems require considerable municipal resources, we propose that the majority of the system is set up only virtually and just a small fraction of the poles are actually physically visited and mapped by city workers. The assumption underlying this proposal is that, in cities with a flat topography, the layout of the lighting infrastructure is such that along relatively long street segments poles are identical and equally spaced. Therefore, we can predict with relatively high accuracy the number of poles and the location of each pole if we just know the location of the first and last pole in the street and the distance between any two poles.

Second, we incorporate into the system an optimization procedure that serves as a decision support system (DSS) for improving the city's lighting infrastructure. This tool uses up-to-date lighting standards from the International Commission on Illumination (abbreviated as CIE following its French name). The CIE determined the required level of lighting for each road type and the optimal level of power needed to achieve this (International Commission on Illumination [CIE], 2010). This data is then compared with the measured power consumption of the system. To decide how to improve the system, we model an Integer Programming problem that finds the optimal improvement scheme subject to the city's budget constraint. This tool can be easily reformulated and updated to address additional constraints that are specific to each municipality.

In the final part of this paper we describe a pilot application of our optimization module. This pilot was conducted using actual data from a neighborhood in a large city in Israel. The optimal scheme of the pilot experiment dictated six changes to the system and resulted with an annual savings of 116,684 ILS on an initial (one-time) investment of 586,181 ILS. 
Dreyfuss \& Giat

\section{LITERATURE REVIEW}

\section{STREET AND THOROUGHFARE LIGHTING}

The most common lamp in street lighting systems is the high-pressure sodium (HPS) lamp (Kostic, Kremic, Djokic, \& Kostic 2013). Many recent studies, however, claim that depending on the purpose, LED lamps should replace the standard HPS light. See, for example, Garcia, Angulo, Gonzalez, Tavizon, and Cardozo (2014) and Jenkins and Bhargava (2015). In contrast, Kostic et al. (2013) show that while LED lamps are excellent alternatives for architectural lighting (such as the illumination of buildings and bridges) they are only sometimes useful for ambient lighting (such as the illumination of pedestrian paths, monuments, fountains, waterfalls, squares, and parks). For street and roadway lightings, however, they find that although using LEDs in lieu of HPS achieves average savings of up to $26 \%$, the total costs are up to 6.44 times higher. Kostic et al. conclude that with current prices, the use of LED lamps is unjustified.

From an environmental point of view, however, there is a general agreement in favor of LED lamps since their lower power consumptions result with lower carbon emission. Moreover, the ability to illuminate at targeted areas as well as the ability to dynamically control lighting levels lead to further energy savings and lower lighting pollution (Farahat, Florea, Lastra, Brañas, \& Sánchez, 2013).

There are different units for measuring light (e.g., candela, footcandle, lumen, lux). In this paper to describe the required level of illumination we use the International System of Unit's (SI) unit candela per square meter $\left(\mathrm{cd} / \mathrm{m}^{2}\right)$. A candela is the base unit for luminous intensity and its operational definition is "the luminous intensity, in a given direction, of a source that emits monochromatic radiation of frequency $540 \times 10^{12}$ hertz and that has a radiant intensity in that direction of $1 / 683$ watt per steradian" (National Institute of Standards and Technology, 2018).

The CIE information that is integrated into the system is used for optimizing the lighting system. In a multi period scheme this has been investigated in Giat (2013) and under strategic condition in Nowik (2009). This has been done in a similar manner in Dreyfuss and Giat (2016) for the gradual improvement of a system to minimize preventive costs. When multiple objectives are needed then the analytic hierarchy process (AHP) model developed by Saaty (2008) is useful. Applications of this model include Rourkela, Mahalik, and Patel (2010) and Atkinson, Bayazit and Karpak (2015). Our approach is to use Integer Programming optimization (see recent applications in Dreyfuss \& Giat, 2016, 2018; Sawik, 2013). This approach requires software optimization tools that are readily available on the market (e.g., Excel for small scale problems, Matlab optimizer, ...).

\section{SMART CITIES AND DIGITAL LITERACY}

In the past decades, a growing number of municipalities have been joining the trend of turning their cities into "smart cities". One dimension of this smart city phenomenon is the street lighting system (e.g., Jennison, Clifford, Horency, Black, \& Ng Zheng, 2017; Rossi, Gaetani, \& Defina, 2016). Based on the understanding that knowledge presents a powerful economic advantage (Nowik \& Zamir, 2003) the methodology for improving the system's power usage usually begin with mapping the entire city system (Beccali, Bonomolo, Ciulla, Galatioto, \& Brano, 2015). Other cities take the more ambitious goal of developing a DSS for all their utilities (Di Sivo \& Ladiana, 2010). The main problem with these approaches, in our specific case, is that they require a tremendous initial investment which may be prohibitive for some cash-constrained municipalities.

The DSS that we develop is used by employees with their smartphones. Not too long ago there were concerns about the digital literacy of non-academic employees (e.g., Bouhnik, Giat, \& Sanderovitch, 2009), which led to the difficulty of integrating computer-based devices into the workplace. These concerns have been significantly reduced in recent years (e.g., Bouhnik, Giat, \& Zarruk, 2016). The 
use of smartphones, tablets, and other computer devices in the workplace is an established practice and they are easily integrated into employees' working operations.

\section{APPLICATION GENERATOR}

To build the information system we use an application generator. There are many such generators in the market, with many of them specializing in specific industries or fields of operation. An application generator enables developers to build applications with relative ease by avoiding the need to program all the aspects of the application. Instead, it provides built in routines and tools, such as the creation of tasks, assets, reports, and access to external internet resources. The built in tools can be used by the programmer with relative ease and therefore, save significant programming time.

For this project we use the Arcsset application generator owned by Nektar Data Systems Corporation (http://www.nektardata.com/resource/products/) from Canada. The following description of Arcsset is taken Crunchbase business information platform (Cruchbase, 2017):

"ArCSSET is a cloud based asset management and mapping solution utilizing a dynamic and flexible platform structure to build mobile data collection processes to report, assess, manipulate, document and archive any data for any asset type. Our uniqueness is that each and every asset is identified by a QR or RFID tag. A simple scan will recall previous history of an asset or upload recently collected data. Asset types can range from construction equipment to oil and gas, utilities, or street signs.

ArCSSET is available on multiple platforms, allowing you to choose between a simple to learn, intuitive environment of iOS devices or GPS enabled heavy duty rugged data collectors running Windows Mobile. ArcSSET records and updates asset GPS location on each scan event so assets are easy to find, inspect, maintain, service, and update.

A user friendly browser interface includes extensive reporting, querying and export functions to meet the needs of to your company field ops or IT department. The integration or addition of ArCSSET's solution to your existing systems is simple and most importantly cost effective. ArsSSET provides multiple benefits to make you more productive and profitable."

\section{THE MODEL}

\section{OVERVIEW}

The model comprises four parts:

- Database: In this part we establish an information system and database that contains all the data related to the city lighting system.

- Mapping algorithm: It is too costly to precisely map all the lighting poles. Instead, we develop an efficient and sufficiently accurate algorithm to map the poles in a fraction of the full cost.

- Energy efficiency: Measuring the current status of energy efficiency. This is done by comparing the actual energy consumption with the theoretical, optimal energy consumption.

- Optimization model: An Integer Programming model that serves as a DSS to improving the city's street lighting system.

Our team included two students whose role was to gather the information needed for the model's components (in particular, the database) and for the implementation pilot.

Before we describe each component of the information system in more detail we explain how a street is defined in our model.

Definition: street - in the paper when we mention "street" we refer to a segment of a fairway that is homogenous in its features. Consider, for example, street X, which stretches in total 5 kilometers: the first two km's are along residential neighborhoods, then it widens to a four lane (total) road for an- 
other $2 \mathrm{~km}$ along residential neighborhoods, and the final $\mathrm{km}$ is alongside a commercial zone. In our model street $\mathrm{X}$ would be treated as three separate streets.

\section{$D A T A B A S E$}

Our examination of various cities and regional councils in Israel resulted with the conclusion that the majority of city governments have no information system or database that manages the lighting poles within the city. This reality prevents the ability to develop an effective plan to improve the lighting system. To develop such a plan, we first describe a database that contains the information that is needed for managing, maintaining, and improving the lighting infrastructure.

Crucially, we argue that the database does not require that all the poles in the system are actually recorded in the database. As we explain in the next section, for most municipalities it is economically restrictive to identify and mark all the poles in the system. Therefore, another feature of the database is that it supports a gradual inclusion of facilities and poles.

The information system is built using the Arcsset application generator, which is a generic, commercial generator owned by Nektar Data Systems corporation from Canada. Arcsset targets utilities, municipalities, and small to medium sized businesses in need of an asset management solution that cannot be addressed with a generic application because of their unique asset type. More importantly for our needs, Arcsset has a strong focus on GIS data integration. As a result, cities have the power to focus on even 'minor' assets such as electric poles and lamps. The main screen of the application is shown in Figure 1.

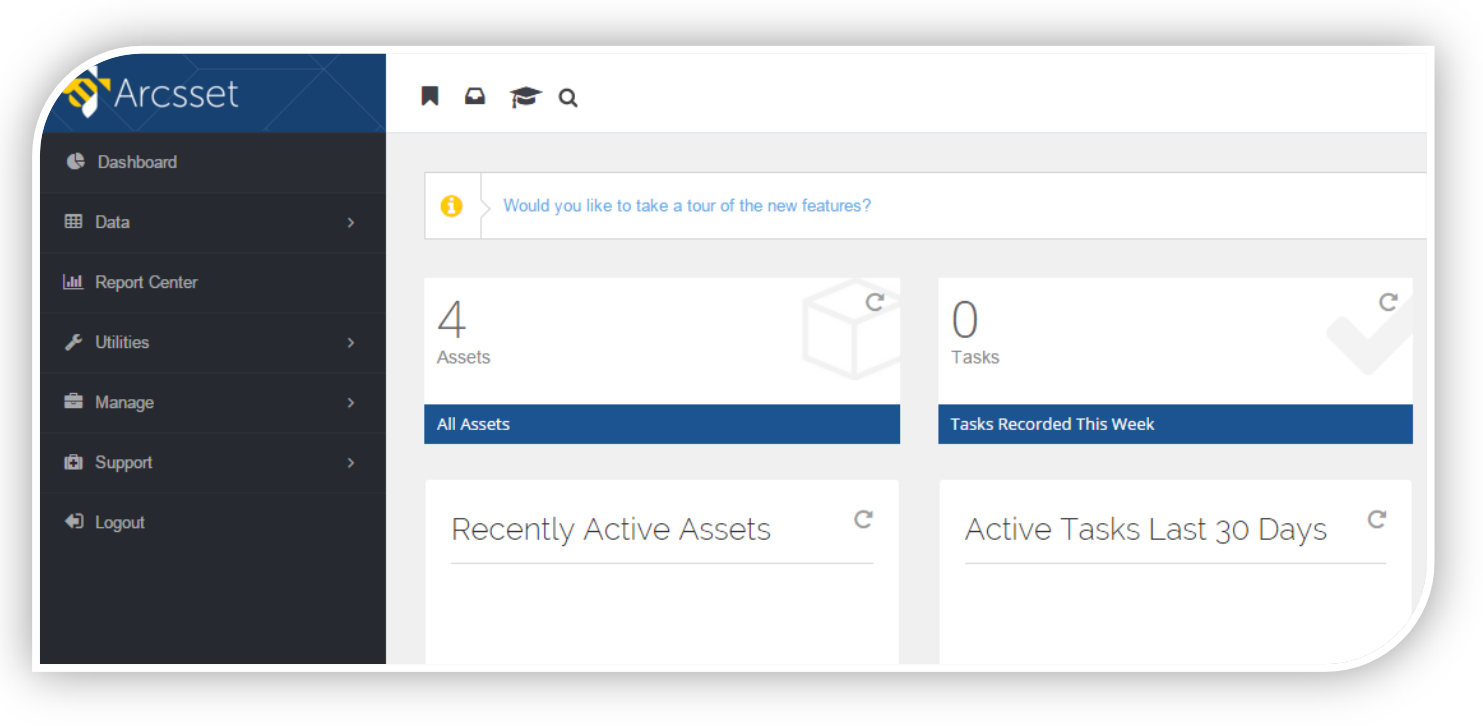

Figure 1. Screen of the Arccsset Application

To understand the needs of the municipality the students interviewed officials in the city government whose many years of tenure in the city ensures their expertise and knowledge about the city's needs.

The conclusion of the analysis is that there are a number of deficiencies in the current situation. First and foremost, there is a general consensus that the current system is inefficient energy-wise leading to waste of money and to environmental issues such as unnecessary carbon emissions and light pollution. In addition, the interviewees pointed out that the repair and maintenance of the lighting systems is inefficient. The reasons for this were varied with a recurring complaint that workers get confused between poles and many times they wasted many hours just locating the lamps to which the repair order referred. 
Evidently, to address both issues, the city needs an inexpensive and accessible management tool with which to manage the system. A database of the lighting system, obviously, is the core of this management tool. There are four components to the development of the database and the management application:

1. Users: The basic tool supports two types of users: managers, maintenance personnel.

2. Assets: An asset can be a lighting pole, lighting fixture, and lighting switchboard. Each asset will contain the following data fields: ID, QR code, picture of the facility, type of switchboard, type of lamp, environment / surrounding description, type of pole, height, connections, number of lamps, flag holders.

3. Tasks: The system is designed to allow adding tasks at the managers' behest. For the basic system the list of tasks includes the following four tasks.

a. Adding an asset: Each time a new physical asset is added to the city's infrastructure, the physical operations are coupled with the task of adding this asset to the database. This task may also happen for existing assets that were not initially added to the system during its initial setup due to limited budget.

b. Repair: When there is a need to repair assets. Each task includes the following information: task ID, the reporting source, type of task, status of task, status of asset, repair by, type of malfunction, picture, and additional details.

c. Tests and control: for example, for examining city blocks to ensure they are operating well.

d. A task list: This task is created by managers. It creates a list of repair and/or test tasks that a single worker or a team of workers are required to execute. For example, each morning the maintenance crew receives their list, which comprises of all the tasks they are to do during the day. Manager's control of their progress is better since they can see how many tasks were successfully completed without the distraction of unnecessary details.

4. Reports: The (partial) list of reports includes:

a. Open tasks. List of assets with repeat failures.

b. Time distribution of completion of tasks (i.e., the number of tasks completed within a month, week, 2 days, and a day).

c. List of tasks completed between any two dates.

d. Tasks listed by user.

e. Tasks listed by task reporter.

f. Statistics for each employee (time and cost).

\section{MAPPING ALGORITHM}

Different municipal governments have different economical resources. Those with considerable resources have the option to physically map all the poles within the city's network including the RFID tagging and numbering.

Unfortunately, most cities do not have the resources for this complete physical mapping. Instead, it is proposed that the majority of the city poles will be mapped virtually as follows.

In Table 1 we list the area and population of the nine largest cities (by population) in Israel. This study was conducted in the city of Netanya, which has approximately 15,000 lighting poles. 
Table 1. Data about major cities in Israel

\begin{tabular}{|l|c|c|c|}
\hline City & Population & Area $\left(\mathrm{km}^{2}\right)$ & Density \\
\hline Jerusalem & 882652 & 125.16 & 7052 \\
\hline Tel Aviv - Yafo & 438818 & 51.81 & 8470 \\
\hline Haifa & 279591 & 63.67 & 4392 \\
\hline Rishon Letziyon & 247323 & 58.70 & 4213 \\
\hline Petah Tiqwa & 236169 & 35.87 & 6584 \\
\hline Ashdod & 221591 & 47.24 & 4691 \\
\hline Netanya & 210834 & 28.95 & 7282 \\
\hline Be'er Sheva & 205810 & 117.50 & 1752 \\
\hline Holon & 190838 & 18.93 & 10083 \\
\hline
\end{tabular}

The virtual mapping's underlying assumption is that for each road the lighting poles arrangement along it is identical, that is, for a typical road the distances between poles are uniform and the poles' features are identical. Thus, by physically mapping the first and last pole in each street and counting the total number of poles in each street, we can map the rest of the poles in the street. Let

$L$ - the number of poles in the street.

$\left(L a t_{1}, L o n g_{1}\right)$ - Latitude and longitude location of first pole in the street.

$\left(\operatorname{Lat}_{L}, \operatorname{Long}_{L}\right)$ - Latitude and longitude location of last pole in the street.

These variables are the input of the mapping algorithm and must be physically measured. The output

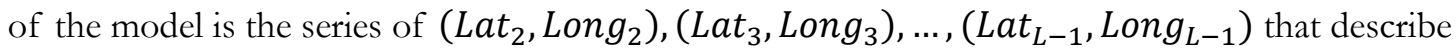
the locations of each of the other poles (except for the first and last, which were physically measured) along the street.

Two compute the distance between two coordinates it is customary to use the Haversine formula or the spherical law of cosines. (See more in Veness, 2017). Since, however, the distances in a typical city are very short, we can assume that, if the city is in a non-hilly or rugged area, then the Earth is flat within any stretch of street and therefore

$$
\begin{aligned}
& L a t_{i}=(i-1)\left(L a t_{L}-L a t_{1}\right) /(L-1)+L a t_{1} \text { for } i=2,3, \ldots, L-1 . \\
& \operatorname{Long}_{i}=(i-1)\left(\operatorname{Long}_{L}-L_{\text {ong }}\right) /(L-1)+\operatorname{Long}_{1} \text { for } i=2,3, \ldots, L-1 \text {. }
\end{aligned}
$$

We emphasize that this approximation is useful only in cities with a relatively flat topography (see more in our discussion of the limitations in the Conclusions section). In the first phase of the system's setup only the first and last poles will have full information. The other poles will be added to the system according to the computed algorithm. Except for the image field, all the fields of the "virtual" poles can be now added. The location fields (i.e., the longitude and the latitude) are computed according to the equations above. The remaining fields will be filled identically to the first and last poles of the street. Whenever a municipal worker has to physically visit any of these poles, (whether is response to a repair request or as part of the routine examination of the physical system) the information that is stored should be updated in case there are discrepancies between the real situation and the one that was initially recorded. 


\section{ENERGY EFFICIENCY}

The purpose of mapping the lightening poles goes beyond facilitating their management and repair. As an added value the database can be used for optimizing the energy efficiency.

We first examine how to sufficiently light a street at minimum cost by using state-of-the-art technology. In Tables 2 and 3 we describe different optimal lighting schemes for a street of the length of 3 $\mathrm{km}$. The data is taken from Tables 2 and 3 from Kostic et al. (2013). The lighting level class is according to the definitions of the mesopic system by the International Commission on Illumination (CIE, 2010)

Table 2. CIE optimal lighting schemes - LED

\begin{tabular}{|c|c|c|c|c|c|c|c|c|}
\hline Street & $\begin{array}{c}\text { Street's } \\
\text { width } \\
\text { (lanes) }\end{array}$ & $\begin{array}{c}\text { Pole's } \\
\text { height } \\
\text { (meter) }\end{array}$ & $\begin{array}{c}\text { Distance be- } \\
\text { tween poles } \\
\text { (meter) }\end{array}$ & Placing & $\begin{array}{c}\text { Lighting } \\
\text { class }\end{array}$ & $\begin{array}{c}\text { Required } \\
\text { level of } \\
\text { lighting } \\
\text { (cd/m })\end{array}$ & $\begin{array}{c}\text { Lamp } \\
\text { power } \\
\text { (watt) }\end{array}$ & $\begin{array}{c}\text { Electricity } \\
\text { consumption }\end{array}$ \\
\hline A & 2 & 7 & 29 & Single-side & M3 & 0.82 & 74 & 8466 \\
\hline B & 2 & 8 & 38 & Single-side & M4 & 0.62 & 74 & 6431 \\
\hline C & 2 & 8 & 45 & Single-side & M5 & 0.39 & 58 & 4275 \\
\hline D & 2 & 8 & 52 & Single-side & M6 & 0.27 & 58 & 3700 \\
\hline E & 3 & 8 & 74 & Opposite & M5 & 0.39 & 58 & 5232 \\
\hline F & 3 & 8 & 22 & Opposite & M2 & 1.33 & 65 & 19531 \\
\hline G & 3 & 8 & 42 & Opposite & M3 & 0.82 & 74 & 11722 \\
\hline H & 3 & 8 & 44 & Opposite & M4 & 0.61 & 58 & 8804 \\
\hline I & 4 & 8 & 16 & Opposite & M1 & 1.82 & 74 & 30606 \\
\hline J & 4 & 8 & 19 & Opposite & M2 & 1.33 & 64 & 22594 \\
\hline K & 4 & 8 & 37 & Opposite & M3 & 0.84 & 74 & 13350 \\
\hline L & 3 & 9 & 13 & Central & M1 & 1.77 & 101 & 51328 \\
\hline M & 3 & 10 & 20 & Central & M2 & 1.32 & 115 & 38203 \\
\hline
\end{tabular}

There are two central characteristics for street lighting. The first is the street's width, which is expressed in the number of driving lanes. The second characteristic is the required level of light needed in each street. This is measures by units of lumens, i.e., the number of candles for each unit of area. The difference between streets is sourced in the different usage of the public fairways. For example, the streets around a shopping center will need more light than a residential, out of the way, alley. 
Table 3. CIE optimal lighting schemes - HPS

\begin{tabular}{|c|c|c|c|c|c|c|c|c|}
\hline Street & $\begin{array}{c}\text { Street's } \\
\text { width } \\
\text { (lanes) }\end{array}$ & $\begin{array}{c}\text { Pole's } \\
\text { height } \\
\text { (meter) }\end{array}$ & $\begin{array}{c}\text { Distance be- } \\
\text { tween poles } \\
\text { (meters) }\end{array}$ & Placing & $\begin{array}{c}\text { Lighting } \\
\text { class }\end{array}$ & $\begin{array}{c}\text { Required } \\
\text { level of } \\
\text { lighting } \\
\text { (cd/m })\end{array}$ & $\begin{array}{c}\text { Lamp } \\
\text { power } \\
\text { (watt) }\end{array}$ & $\begin{array}{c}\text { Electricity } \\
\text { consumption }\end{array}$ \\
\hline A & 2 & 8 & 34 & Single-side & M3 & 1.09 & 100 & 10232 \\
\hline B & 2 & 7 & 28 & Single-side & M4 & 0.73 & 70 & 8694 \\
\hline C & 2 & 8 & 41 & Single-side & M5 & 0.48 & 70 & 5957 \\
\hline D & 2 & 8 & 44 & Single-side & M6 & 0.39 & 70 & 5555 \\
\hline E & 3 & 8 & 68 & Opposite & M5 & 0.48 & 70 & 7165 \\
\hline F & 3 & 8 & 31 & Opposite & M2 & 1.57 & 100 & 22310 \\
\hline G & 3 & 7 & 33 & Opposite & M3 & 0.96 & 70 & 14651 \\
\hline H & 3 & 8 & 36 & Opposite & M4 & 0.85 & 70 & 13524 \\
\hline I & 4 & 8 & 24 & Opposite & M1 & 1.95 & 100 & 28980 \\
\hline J & 4 & 8 & 28 & Opposite & M2 & 1.54 & 100 & 24840 \\
\hline K & 4 & 7 & 28 & Opposite & M3 & 0.98 & 70 & 17388 \\
\hline L & 3 & 10 & 38 & Central & M1 & 2.14 & 250 & 45425 \\
\hline M & 3 & 10 & 32 & Central & M2 & 1.44 & 150 & 32430 \\
\hline
\end{tabular}

Table 4 is the reference table for the optimal lighting level when the optimization criterion is minimum electricity consumption. That is, we disregard the different cost of HPS and LED lamps and choose for each street type the lamp with the lowest electricity consumption.

Table 4. Optimal lighting schemes LED/HPS

\begin{tabular}{|c|c|c|c|c|c|c|c|c|}
\hline Street & $\begin{array}{c}\text { Lamp } \\
\text { Type }\end{array}$ & $\begin{array}{c}\text { Street's } \\
\text { width } \\
\text { (lanes) }\end{array}$ & $\begin{array}{c}\text { Pole's } \\
\text { height } \\
\text { (meter) }\end{array}$ & $\begin{array}{c}\text { Distance be- } \\
\text { tween poles } \\
\text { (meter) }\end{array}$ & Placing & $\begin{array}{c}\text { Lighting } \\
\text { class }\end{array}$ & $\begin{array}{c}\text { Lamp } \\
\text { power } \\
\text { (watt) }\end{array}$ & $\begin{array}{c}\text { Electricity } \\
\text { consumption }\end{array}$ \\
\hline A & LED & 2 & 7 & 29 & Single-side & M3 & 74 & 8466 \\
\hline B & LED & 2 & 8 & 38 & Single-side & M4 & 74 & 6431 \\
\hline C & LED & 2 & 8 & 45 & Single-side & M5 & 58 & 4275 \\
\hline D & LED & 2 & 8 & 52 & Single-side & M6 & 58 & 3700 \\
\hline E & LED & 3 & 8 & 74 & Opposite & M5 & 58 & 5232 \\
\hline F & LED & 3 & 8 & 22 & Opposite & M2 & 65 & 19531 \\
\hline G & LED & 3 & 8 & 42 & Opposite & M3 & 74 & 11722 \\
\hline H & LED & 3 & 8 & 44 & Opposite & M4 & 58 & 8804 \\
\hline I & HPS & 4 & 8 & 24 & Opposite & M1 & 100 & 28980 \\
\hline J & LED & 4 & 8 & 19 & Opposite & M2 & 64 & 22594 \\
\hline K & LED & 4 & 8 & 37 & Opposite & M3 & 74 & 13350 \\
\hline L & HPS & 3 & 10 & 38 & Central & M1 & 250 & 45425 \\
\hline M & HPS & 3 & 10 & 32 & Central & M2 & 150 & 32430 \\
\hline
\end{tabular}


In the next step, we consider the characteristics of the streets in the city. In Table 5 we take a short sample of 10 streets.

Table 5. Lighting details of a sample of the city's streets

\begin{tabular}{|l|c|c|c|c|c|c|c|c|c|}
\hline Street & $\begin{array}{c}\text { Lamp } \\
\text { type }\end{array}$ & $\begin{array}{c}\text { Street's } \\
\text { length } \\
\text { (km) }\end{array}$ & $\begin{array}{c}\text { Street's } \\
\text { width } \\
\text { lanes) }\end{array}$ & $\begin{array}{c}\text { Pole's } \\
\text { height } \\
\text { (meter) }\end{array}$ & $\begin{array}{c}\text { Distance } \\
\text { between } \\
\text { poles (me- } \\
\text { ter) }\end{array}$ & Placing & $\begin{array}{c}\text { Lighting } \\
\text { class }\end{array}$ & $\begin{array}{c}\text { Lamp } \\
\text { power } \\
\text { (watt) }\end{array}$ & $\begin{array}{c}\text { Measured } \\
\text { electricity } \\
\text { consumption }\end{array}$ \\
\hline Hertzel & LED & 2.72 & 2 & 7 & 40 & Single-side & M3 & 74 & 8466 \\
\hline Tzoran & LED & 3.50 & 2 & 7 & 36 & Single-side & M5 & 58 & 13812 \\
\hline Weitzman & LED & 2.76 & 2 & 7 & 46 & Single-side & M6 & 58 & 5034 \\
\hline Rabbi Kook & LED & 3.91 & 2 & 7 & 27 & Single-side & M5 & 74 & 5349 \\
\hline Peanes & LED & 3.86 & 2 & 7 & 51 & Single-side & M3 & 58 & 14922 \\
\hline Gordon & LED & 2.38 & 2 & 7 & 38 & Single-side & M3 & 74 & 8538 \\
\hline King Solomon & LED & 2.14 & 2 & 7 & 32 & Single-side & M5 & 58 & 6580 \\
\hline HaEgoz & LED & 2.01 & 2 & 7 & 52 & Single-side & M6 & 74 & 9625 \\
\hline Ben Gurion & LED & 2.09 & 2 & 7 & 30 & Single-side & M6 & 74 & 10652 \\
\hline King David & LED & 2.67 & 2 & 7 & 46 & Single-side & M4 & 58 & 7645 \\
\hline
\end{tabular}

In the next step we find the street type (A...M) that fits the street whose efficiency we wish to measure. The algorithm we choose is as follows.

For example, Hertzel street is a two lane street with Lighting class level of M3, and, therefore, Hertzel is comparable to street type A. In Table 6 we detail to which each of the sample streets is compared and compute the efficiency according to the following formula:

Efficiency $=$ (Baseline Power Consumption / Measured Electricity consumption $) *$ length ratio

Where the length ration is the street's length divided by 3 , since the street types are all measured in lengths of $3 \mathrm{~km}$.

Table 6. Lighting details of a sample of the city's streets

\begin{tabular}{|l|c|c|c|c|c|}
\hline Street & $\begin{array}{c}\text { Comparable to } \\
\text { baseline street }\end{array}$ & $\begin{array}{c}\text { Street's } \\
\text { length }(\mathrm{km})\end{array}$ & $\begin{array}{c}\text { Measured electricity } \\
\text { consumption }\end{array}$ & $\begin{array}{c}\text { Baseline power con- } \\
\text { sumption per 3km }\end{array}$ & Efficiency \\
\hline Hertzel & A & 2.72 & 8466 & 8466 & $91 \%$ \\
\hline Tzoran & C & 3.50 & 13812 & 4275 & $36 \%$ \\
\hline Weitzman & D & 2.76 & 5034 & 3700 & $68 \%$ \\
\hline Rabbi Kook & C & 3.91 & 5349 & 4275 & $104 \%$ \\
\hline Peanes & A & 3.86 & 14922 & 8466 & $73 \%$ \\
\hline Gordon & A & 2.38 & 8538 & 8466 & $79 \%$ \\
\hline King Solomon & C & 2.14 & 6580 & 4275 & $46 \%$ \\
\hline HaEgoz & D & 2.01 & 9625 & 3700 & $26 \%$ \\
\hline Ben Gurion & D & 2.09 & 10652 & 3700 & $24 \%$ \\
\hline King David & B & 2.67 & 7645 & 6431 & $75 \%$ \\
\hline
\end{tabular}


In Table 6 we emphasize the different levels of inefficiencies using a coloring scheme so that the least efficient streets are colored red and those that are reasonably efficient are colored green. Note that it is possible to have a street with an efficiency higher than $100 \%$, although this should be technically impossible. This could happen because of a number of reasons, such as that the current light is less than the needed (and therefore the actual power consumption is low), or that the lights were out due to malfunctioning. To overcome these "measurement errors" the actual power usage should be measured a number of times.

\section{OPTIMIZATION MODEL}

Greedy model: One approach to using the data collected in the previous step is to sort all street segments by their efficiency level and address the most inefficient first. This is a "greedy" algorithm and in our problem is not an optimal. To understand why, consider streets $\mathrm{X}$ and $\mathrm{Y}$ and assume that street $\mathrm{X}$ is very long and with $80 \%$ efficiency whereas street $\mathrm{Y}$ is very short and $75 \%$ efficiency. The greedy approach dictates that one first improves street $Y$ because of its low efficiency, although, in reality improving street $\mathrm{X}$ will attain much higher savings due to the fact that it is much longer.

As an alternative to the naïve greedy approach, we use Integer Programming. In general, the IP problem will find the improvement scheme that maximizes the reduction in energy consumption subject to a budget constraint. The reason we assume a budget constraint is that in the municipal financial reality, even when promised future savings, cash-strapped municipalities are unable to budget the needs sums, but instead, at most, can budget a limited sum for maintenance and cost reductions.

The IP problem's input is:

1. Data about each street's electricity consumption.

2. The cost of each energy improvement alternative.

3. Other constraints: budget, limitations on certain alternatives.

There are three alternatives for improvement:

1. Do nothing

2. Replacing only the lamps

3. Changing the poles and the lamps

4. Replacing the entire lighting infrastructure in the street

Variables

$I$ - The number of streets in the city

$N_{i}$ - The number of poles in street $i$

$D_{i}$ - Normalized actual energy consumption in street $i$

$B$ - Budget dedicated for the energy improvement project

$C_{j}$ - The cost per pole of alternative $j$

$O_{i, j}$ - The expected normalized energy consumption in street $i$ after implementing alternative $j$

$X_{i, j}$ - An indicator variable that is equal to one if alternative $j$ is implemented in street $i$ and zero, otherwise. 
The objective function maximizes the difference between the normalized current energy consumption and the normalized expected energy consumption. Accordingly, it is given by:

$$
\operatorname{MAX}\left(\sum_{i=1}^{I} D_{i}-\sum_{j=1}^{4} \sum_{i=1}^{I} X_{i, j} \times O_{i, j}\right)
$$

The constraints are given by:

Budget constraints:

$$
\sum_{i=1}^{I} \sum_{j=1}^{4} X_{i, j} \times N_{i} \times C_{j} \leq B
$$

Only one alternative may be chosen:

$$
\sum_{j=1}^{4} X_{i, j}=1 \quad \forall i
$$

Variable values are binary: $X_{i, j}=$ Binary

\section{IMPLEMENTATION PILOT}

We conducted an implementation pilot for 36 streets in the city of Netanya and executed the IP optimization procedure. In the left part of Table 7 we provide the problem's inputs, which include the cost for each option $\left(O_{i, 0}, \ldots, O_{i, 3}\right)$, the number of streets, the number of poles in each street and the power consumption for each street if we implement each of the alternatives. The values of the other model parameter are $C_{1}=0, C_{2}=1500, C_{3}=2250, C_{4}=3500, I=36, B=600,000$.

Remark 1: In the current situation there are many streets whose lighting level is not sufficiently luminous. While the city does not mind leaving the street at its current state of light, it requires that if any change is to be done, it must bring the street to the required level of lighting, Therefore, in some of the entries of Table 7 we get paradoxical results in which choosing alternative 1 or 2 results in higher level of consumption than doing nothing.

Remark 2: This project is defined as improving power consumption. Therefore, we do not introduce into the objective function the benefit of improving the lighting level. Accordingly, those streets that use little power because they are poorly lit will not be candidates for improvement since the city will require their lighting level to be raised and as a consequence their energy consumption will increase.

A similar problem rises with streets whose distance between poles is $20 \%$ more than the standard of CIE. With these streets we do not allow lamp or pole replacement, but only alternative 3 . The entries of $O_{i, 1}$ and $O_{i, 2}$ in Table 7 are 'NA' and in the IP problem was given a value that greatly exceeds the budget to ensure these alternatives are never chosen. 
Table 7. IP problem's input values and output

\begin{tabular}{|c|c|c|c|c|c|c|}
\hline Street i & $\mathrm{Ni}$ & Oi0 & Oi1 & Oi2 & Oi3 & Output \\
\hline 1 & 68 & 8466 & 8846 & 8846 & 7679 & 0 \\
\hline 2 & 97 & 13812 & NA & NA & 16128 & 0 \\
\hline 3 & 60 & 5034 & 3475 & 3475 & 4625 & 0 \\
\hline 4 & 145 & 5349 & NA & NA & 6963 & 0 \\
\hline 5 & 76 & 14922 & NA & NA & 19200 & 0 \\
\hline 6 & 63 & 8538 & 11137 & 11137 & 6782 & 0 \\
\hline 7 & 67 & 6580 & NA & NA & 4689 & 0 \\
\hline 8 & 39 & 9625 & 3346 & 3346 & 6452 & 1 \\
\hline 9 & 70 & 10652 & NA & NA & 7421 & 0 \\
\hline 10 & 58 & 7645 & 9216 & 9216 & 6814 & 0 \\
\hline 11 & 125 & 12857 & NA & NA & 15523 & 0 \\
\hline 12 & 70 & 12285 & 3955 & 3955 & 12613 & 1 \\
\hline 13 & 76 & 12834 & 3625 & 3625 & 15551 & 1 \\
\hline 14 & 151 & 11656 & NA & NA & 14115 & 0 \\
\hline 15 & 65 & 5136 & 6529 & 6529 & 3780 & 0 \\
\hline 16 & 66 & 10196 & 3625 & 3625 & 10685 & 0 \\
\hline 17 & 72 & 10320 & NA & NA & 4702 & 3 \\
\hline 18 & 35 & 18469 & NA & NA & 10743 & 0 \\
\hline 19 & 38 & 17563 & NA & NA & 11709 & 0 \\
\hline 20 & 75 & 17592 & $\mathrm{NA}$ & NA & 17246 & 0 \\
\hline 21 & 79 & 12000 & NA & NA & 7616 & 0 \\
\hline 22 & 69 & 25863 & NA & NA & 27484 & 0 \\
\hline 23 & 46 & 15269 & NA & NA & 12164 & 0 \\
\hline 24 & 42 & 9790 & NA & NA & 7062 & 0 \\
\hline 25 & 76 & 26732 & NA & NA & 29895 & 0 \\
\hline 26 & 44 & 12247 & NA & NA & 5258 & 0 \\
\hline 27 & 62 & 18479 & NA & NA & 13009 & 0 \\
\hline 28 & 52 & 5962 & NA & NA & 3641 & 0 \\
\hline 29 & 56 & 14687 & NA & NA & 8832 & 3 \\
\hline 30 & 44 & 15423 & NA & NA & 11660 & 0 \\
\hline 31 & 45 & 7284 & NA & NA & 3802 & 3 \\
\hline 32 & 96 & 7557 & NA & NA & 8968 & 0 \\
\hline 33 & 180 & 9379 & NA & NA & 10680 & 0 \\
\hline 34 & 83 & 11108 & 8700 & 8700 & 12278 & 0 \\
\hline 35 & 166 & 13589 & NA & NA & 16529 & 0 \\
\hline 36 & 57 & 28152 & NA & 37500 & 21452 & 0 \\
\hline
\end{tabular}


The output of the pilot experiment is given in the right column of Table 7. In total there are 6 recommended changes. The lamps in streets 8,12 , and 13 should be replaced, and the infrastructure of streets 17, 29, and 31 should be replaced.

The budget required to make these changes is $586,181 \mathrm{ILS}$. The expected annual reduction in power consumption is $220,159 \mathrm{kWh}$, which in current prices of 0.53 ILS per $\mathrm{kWh}$ is equal to 116,684 ILS.

\section{CONCLUSIONS}

In this paper we present an information system for urban lighting poles that serves, in addition, as a DSS for investment in improving the lighting infrastructure. The most important advantage of this system is the ability to set it up inexpensively and quickly, thus allowing even cash-strapped local governments to implement it.

The main limitation of our model is that, to significantly reduce the cost of physically mapping (and tagging) all the city assets, we assume that along straight (linear) street segments pole characteristics and the distance between the poles do not vary. This is not always true and could result with incorrect mapping that will have to be continually corrected each time employees identify discrepancies between the system and reality. Moreover, this assumes that the city is designed according to a city grid and not winding roads. Therefore, this element of the model can be applied only to neighborhoods or cities with a flat geographical topography for which streets mostly follow straight lines.

To demonstrate the system's benefits, we conducted a pilot demonstration using data from a neighborhood within a city in Israel. This pilot experiment shows that significant long term savings may be obtained by using such a system, in addition to the service and managerial advantages.

An expansion of the project to a city wide application will requires a considerable budget, but promises very positive returns in future energy costs as well as the reduction of light pollution and carbon emissions.

\section{REFERENCES}

Atkinson, M. A., Bayazit, O., \& Karpak, B. (2015). A case study using the analytic hierarchy process for IT outsourcing decision making. International Journal of Information Systems and Supply Chain Management (IJISSCM), 8(1), 60-84. https://doi.org/10.4018/ijisscm.2015010104

Beccali, M., Bonomolo, M., Ciulla, G., Galatioto, A., \& Brano, V. L. (2015). Improvement of energy efficiency and quality of street lighting in South Italy as an action of sustainable energy action plans. The case study of Comiso (RG). Energy, 92, 394-408. https://doi.org/10.1016/j.energy.2015.05.003

Bouhnik, D., Giat, Y., \& Sanderovitch, Y. (2009). Asynchronous learning sources in a high-tech organization. Journal of Workplace Learning, 21(5), 416-430. https://doi.org/10.1108/13665620910966811

Bouhnik, D., Giat, Y., \& Zarruk, I. (2016). University procurement officers' use of technology when seeking information. Issues in Informing Science and Information Technology, 13, 195-208. https://doi.org/10.28945/3473

Crunchbase. (2017). ArcSSET: Asset Management \& Mapping Solutions. Retrieved December 16, 2017 from https://www.crunchbase.com/organization/arcsset

Di Sivo, M., \& Ladiana, D. (2011). Decision-support tools for municipal infrastructure maintenance management. Procedia Computer Science, 3, 36-41. https://doi.org/10.1016/j.procs.2010.12.007

Dreyfuss, M., \& Giat, Y. (2016). Identifying security risk modules in a university's information system. In Proceedings of Informing Science \& IT Education Conference (Vol. 2016, pp. 41-51).

Dreyfuss, M., \& Giat, Y. (2018). Insider-risk support model for an academic institution's information system. Information Resources Management Journal (IRMJ), 31(1). https://doi.org/10.4018/IRMJ.2018010104

Garcia, R. B., Angulo, G. V., Gonzalez, J. R., Tavizon, E. F., \& Cardozo, J. I. H. (2014, October). LED street lighting as a strategy for climate change mitigation at local government level. In Global Humanitarian Technology Conference (GHTC), 2014 IEEE (pp. 345-349). IEEE. https://doi.org/10.1109/GHTC.2014.6970303 
Giat, Y. (2013). The effects of output growth on preventive investment policy. American Journal of Operations Research, 3(06), 474. https://doi.org/10.4236/ajor.2013.36046

Governing. (2017). Bankrupt cities, municipalities list and map. Retrieved December 16, 2017 from http://www.governing.com/gov-data/municipal-cities-counties-bankruptcies-and-defaults.html

Farahat, A., Florea, A., Lastra, J. L. M., Brañas, C., \& Sánchez, F. J. A. (2015). Energy efficiency considerations for LED-based lighting of multipurpose outdoor environments. IEEE Journal of Emerging and Selected Topics in Power Electronics, 3(3), 599-608. https://doi.org/10.1109/JESTPE.2015.2453231

International Commission of Illumination (CIE). (2010). Lighting of roads for motor and pedestrian traffic. Retrieved April 15, 2018 from http://www.cie.co.at/publications/lighting-roads-motor-and-pedestrian$\underline{\text { traffic }}$

Jenkins, D., \& Bhargava, A. (2015). LED lighting: Maximizing the reliability, safety, and efficiency of light fixtures in hazardous environments. IEEE Industry Applications Magaqine, 21(1), 64-67. https://doi.org/10.1109/MIAS.2014.2345829

Jennison, R., Clifford, C., Horency, C., Black, B., \& Ng Zheng, E. (2017). Smart street lighting: Campus pilot. Ohio State University. Retrieved January 21, 2018 from http://hdl.handle.net/1811/80673

Johansson, M., Pedersen, E., Maleetipwan-Mattsson, P., Kuhn, L., \& Laike, T. (2014). Perceived outdoor lighting quality (POLQ): A lighting assessment tool. Journal of Environmental Psychology, 39, 14-21. https://doi.org/10.1016/i.jenvp.2013.12.002

Jurvansuu, M., \& Belloni, K. (Eds.). (2013). Productivity leap with IoT: Visions of the Internet of Things with a special focus on global asset management and smart lighting. VTT. Retrieved from http://www.vtt.fi/inf/pdf/visions/2013/V3.pdf

Kostic, A. M., Kremic, M. M., Djokic, L. S., \& Kostic, M. B. (2013). Light-emitting diodes in street and roadway lighting - A case study involving mesopic effects. Lighting Research \& Technology, 45(2), 217-229. https://doi.org/10.1177/1477153512440771

National Institute of Standards and Technology. (2018). Retrieved April 15, 2018 from https://www.nist.gov/pml/weights-and-measures/si-units-candela

Nowik, I. (2009). The game motoneurons play. Games and Economic Behavior, 66(1), 426-461. https://doi.org/10.1016/i.geb.2008.04.016

Nowik, I., \& Zamir, S. (2003). The game for the speed of convergence in repeated games of incomplete information. International Journal of Game Theory, 31(2), 203-222. https://doi.org/10.1007/s001820200101

Rourkela, S., Mahalik, D., \& Patel, G. (2010). Information technology implementation prioritization in supply chain: An integrated multi criteria decision making approach. International Journal of Information Systems and Supply Chain Management (IJISSCM), 3(4), 83-96. http://dx.doi.org/10.4018/978-1-4666-0918-1.ch002

Rossi, C., Gaetani, M., \& Defina, A. (2016). AURORA: An energy efficient public lighting IoT system for smart cities. ACM SIGMETRICS Performance Evaluation Review, 44(2), 76-81. https://doi.org/10.1145/3003977.3004000

Saaty, T. L. (2008). Decision making with the analytic hierarchy process. International Journal of Services Sciences, 1(1), 83-98. https://doi.org/10.1504/IJSSci.2008.01759

Sawik, T. (2013). Selection of optimal countermeasure portfolio in IT security planning. Decision Support Systems, 55(1), 156-164. https://doi.org/10.1016/j.dss.2013.01.001

Veness, C. (2017). Calculate distance, bearing and more between Latitude/Longitude points. Retrieved December 16, 2017 from https://www.movable-type.co.uk/scripts/latlong.html 


\section{BIOGRAPHIES}

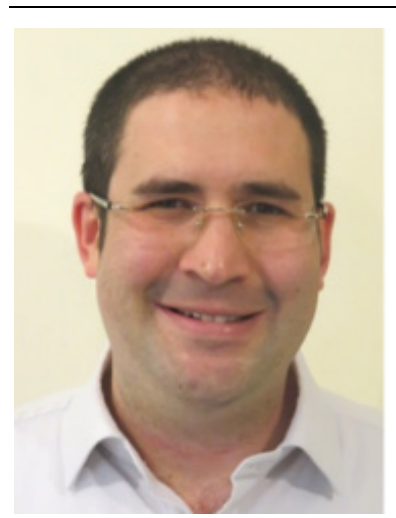

Dr. Michael Dreyfuss is a tenured faculty member in the Department of Industrial Engineering and Management in the Jerusalem College of Technology. He holds a Ph.D. and an MSc. in Industrial Engineering from the Ben Gurion University of the Negev, a B.Sc. in Computer Sciences and B.Sc. in Industrial Engineering and Management from the Jerusalem College of Technology.

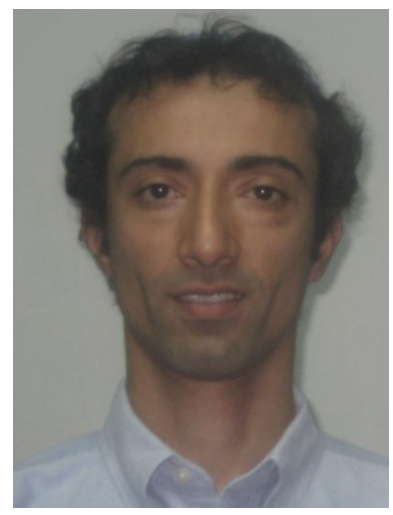

Dr. Yahel Giat is a tenured faculty member in the Department of Industrial Engineering and Management in the Jerusalem College of Technology. He holds a Ph.D. and an MSc. in Industrial Engineering from the Georgia Institute of Technology, an MSc. in Economics, a B.Sc. in Electrical Engineering and B.A. in Computer Sciences from the Israel Institute of Technology. 